Reflections on the role of per diems in international development projects: barriers and enablers to the project cycle

Authors: Yvonne Erasmus, Desyreé Lötter, Natalie Rebelo Da Silva, Ruth Stewart

Dr Yvonne Erasmus (corresponding author)

Africa Centre for Evidence (ACE), University of Johannesburg, South Africa

Email: yerasmus@uj.ac.za

Tel: 0115591909

Postal address: House 2, Research Village, Bunting Road Campus, PO Box 524, Auckland

Park, 2006, Johannesburg, South Africa

Ms Desyreé Lötter

Africa Centre for Evidence (ACE), University of Johannesburg, South Africa

Email: eerysed@gmail.com

Tel: 0115591909

Postal address: House 2, Research Village, Bunting Road Campus, PO Box 524, Auckland Park, 2006, Johannesburg, South Africa

Ms Natalie Rebelo Da Silva

Email: natalierds@uj.ac.za

Tel: 0115591909

Postal address: House 2, Research Village, Bunting Road Campus, PO Box 524, Auckland Park, 2006, Johannesburg, South Africa

Prof Ruth Stewart

Email: ruths@uj.ac.za

Tel: 0115591909

Postal address: House 2, Research Village, Bunting Road Campus, PO Box 524, Auckland Park, 2006, Johannesburg, South Africa 


\section{Reflections on the role of per diems in international development projects: barriers and enablers to the project cycle $^{1}$}

The concept of what a per diem is and who should receive one is a complex idea that, within the development context, can either support or hinder the achievement of development projects' goals. This paper seeks to explain the evolving nature of per diems and their use within the development context; explore how they serve as barriers or enablers in achieving project goals; and touch on their impact on the development project cycle. Through a threeyear-long internationally-funded development programme in Malawi and South Africa, the authors compare lessons drawn from their experience to existing literature to determine the practicalities of paying per diems and address the question: to what extent do per diems support or hinder international development projects?

\section{Introduction}

The term 'per diem' (henceforth per diem/s) has Latin origins that can be traced back to 1809. Its meaning of 'by the day' refers to an amount determined in advance to act as a daily allowance. Its original application was intended for sales representatives and civil servants to cover expenses while travelling during extended periods of time. The per diem would include payment from a wider variety of role-players, such as employers more generally, as well as development agencies to cover approved employee expenditure. ${ }^{2}$

Per diems are relevant to the field of international development in two ways. First, employees of international donor agencies receive per diems for trips to field-sites, for instance. This is in line with the more traditional use of per diems to make provision for travelling expenses. However, such payments have been problematized as they often vastly exceed what staff from local non-governmental organisations (NGOs) receive. Second, per diems are also used in-country in international development projects to cover travel and food expenses of civil servants and project beneficiaries. This has been extended as a way in which to compensate beneficiaries for participation in international development projects.

How and why per diems are paid in development projects is worth examining for both the macro- and micro-level impacts. At a macro-economic level per diems can be viewed within the context of 'large sums of money flowing in and out of Africa in the name of research and implementation'. ${ }^{3}$ This is in part because 'an increasingly considerable portion of public spending is allotted to allowances and per diems, usually in connection with seminars and workshops. This is especially the case as capacity building is a central concern of development efforts notably in Africa'. ${ }^{4}$ Examples of scale mentioned in the literature include that in 2009 the Government of Tanzania spent USD 390 million on allowances ${ }^{5}$. On a more micro-level, the payment of per diems raises the question of individuals' incentives to participate in projects, especially as a result of the disproportionate amounts paid to them - a study conducted in two districts in Burkina Faso found that per diem income exceeded health workers' salaries ${ }^{6}$, while in Mozambique health workers that participated in a three-week provincial workshop received the equivalent of 18-months' salary from the development agency? 
Our interest in the topic of per diems stems from our three-year programme funded by [text removed for purposes of anonymization during peer review] working in Malawi ${ }^{8}$ where the topic of per diems was frequently discussed at various times during our project inception phase and year of implementing there $(2014-2015)$. This emphasis on the payment of per diems has sparked our interest in the experience of other development projects working in Malawi specifically and elsewhere in Africa.

This paper explores the ways in which per diems can act as enablers and barriers in international development projects, affecting different aspects of the project lifecycle at different times. The need for further discussions on per diems is supported by the literature where a shortage is mentioned ${ }^{9}$, as well as 'that these issues have rarely been raised globally, as if discussing it is almost off-limits in the development community'10.

\section{Use of per diems in the African context}

In order to understand the payment of per diems it is necessary to acknowledge their complexity, for example what constitutes a per diem, how they apply to different sectors, the extent of their use, and what purpose they serve. ${ }^{11}$ The payment of per diems can serve a number of different functions for the organisation paying them: they serve to cover travelrelated expenses ${ }^{12}$; they encourage attendance at professional development courses or meetings ${ }^{13}$ and the uptake of activities that might otherwise be difficult to carry out ${ }^{14}$; they act as financial incentives that increase the job satisfaction of employees ${ }^{15}$; and it allows an organisation to streamline its financial accounting systems ${ }^{16}$ by 'simplifying administration by eliminating the controls needed in a system of reimbursing actual costs'17.

Allowances can be distributed in different ways. Comparative work across Tanzania, Malawi and Ethiopia demonstrated this: for example, in Tanzania 'some allowances are linked to a specific position or situation, referred to as remunerative allowances, and include for example "disturbance allowance" (if relocating), outfit allowance and housing allowance. Other allowances are discretionary benefits, often referred to as duty-facilitating allowances, and include overtime and special duty allowances, honoraria for outstanding performance and sitting allowances. ${ }^{\prime 18}$ However, although some overlap exists, in Malawi distinction is made conceptually between the intended functions of allowances: 'income-enhancing or remunerative allowances...and performance or work-facilitating and work-enhancing allowances. ${ }^{\prime 19}$ Per diem rates can also vary by location, by sponsor and by staff level. ${ }^{20}$ There are different views on whether it is fair that rates vary by seniority ${ }^{21}$ as the (mis)use of per diems by more senior staff is sometimes highlighted less as their power obfuscates this ${ }^{22}$.

It is the income-enhancing element of per diems that receive some attention in the literature because 'while these allowances are only meant to be compensatory, they tend to assume the character of additional salary payment in countries where salary levels are generally low...[and] may contribute significantly to total income. ${ }^{23}$ When civil servants in Uganda and Tanzania were surveyed three-quarters of the sample saw allowances as equally important to a basic salary for their total income, while 13 percent were of the view that allowances were much more important than salaries ${ }^{24}$. However, a cautionary note is necessary when speaking about low salaries and what the comparators are as civil servants are sometimes more well- 
off than other professional groupings, such as those working in non-governmental organisations (NGO) for instance. Such income supplementation does not exclusively apply to civil servants, and examples exist of it being an important means for health workers who receive low salaries or who experience delays in salary payments to supplement their income ${ }^{25}$. If per diems go hand-in-hand with the topping up of salaries it is apt to ask what the implications of the institutionalisation of per diems is for salary levels. Such longer-term implications might include the undermining of the fair payment of salaries ${ }^{26}$ because if per diems are perceived as salary-supplements, and an expected given in the [development] field, local salaries will continue to remain low. ${ }^{27}$ A final aspect that might lead to increases in requests for the amount of per diem payments received in order to top up salaries is the imbalance between per diems allocated to international NGO staff and/or donor aid workers and local staff to attend the same event, for example 'a local person might receive USD 10 to attend a workshop, but someone from the WHO or UN attending the same workshop might receive close to USD 300. This might further reinforce power imbalances and also make local people ask for increases in per diems. If the problem is to be examined, all of the actors and the structural context that allow it should be examined. ${ }^{28}$

Differences of opinion exist on what per diems might mean for how development projects are implemented and the field of international development more generally. More critical views argue that per diems 'undermine employment rights, undermine the economy, undermine financial management and good governance systems, undermine implementation of projects, undermine other projects and finally undermine monitoring, evaluation and learning. ${ }^{29}$ Openness is emphasised as per diems are seen as going to the heart of what development projects aim to achieve.' ${ }^{30}$ The payment of per diems are not necessarily equated with corruption as regulatory frameworks do exist in some countries, although not all. ${ }^{31}$ And economists might argue that individuals are merely maximizing their personal utility. ${ }^{32}$ But when asking whether per diems pose a challenge in the implementation of development projects it has been pointed out that who poses the question is important western public health professionals have raised concerns, but it has to be asked whether people in developing countries also perceive the negative effects of per diems for development projects. ${ }^{33}$

\section{Approaches to studying the topic}

This paper draws on three main sources, the first of which is the existing literature on per diems as they relate to the field of international development. These were identified through searching academic peer reviewed databases and locating grey literature on the topic. Drawing on the advice in the existing literature on per diems, the paper also attempts to provide the perspectives of different actors in the development field ${ }^{34}$ by drawing on twelve interviews conducted over a two-month period between February and April 2016. These included people that have played different roles in development projects, for example those who have funded projects, been implementers of projects, or who have been beneficiaries of projects in Malawi specifically, and some also in other African countries. Finally the paper draws on the first-hand experiences of the authors who are part of a broader team that have been implementing [text removed for the purposes of anonymization during peer review]. Although our experiences are only observational and anecdotal, they add value in testing how our experience resonates with the existing literature and can add to what is already known 
and documented about the role of per diems in international development. The interest in writing this paper stems particularly from project conceptualisation and implementation in Malawi (2014 - 2015) as per diems were a component that affected the project. All data were analysed using a thematic analysis framework ${ }^{35}$.

Whilst this paper only looks at per diems in the context of Africa, and specifically Malawi, it adds to the existing body of knowledge by drawing together the views of different roleplayers in the development field, e.g. international donors, local NGOs, civil servants. In addition, where much of the existing literature on per diems focuses on the health sector ${ }^{36}$ this paper takes a broader view and looks at per diems in areas outside of health. Finally, as set out in later sections of this paper, our analysis of the data indicate that per diems affect all aspects of the project planning and management cycle, which is a novel contribution to the literature on per diems.

\section{Per diems as an enabler in development projects}

The literature suggests that per diems can have benefits on three levels - individual, organisational and at the level of international development, although these levels are not mutually exclusive. The personal benefits of per diems focus on two dimensions. The first, and most predominant, relates to per diems acting as a top-up to salary, e.g. providing additional salary for paying household expenses, ${ }^{37}$ allowing families to save for bigger expenses and to pay back loans ${ }^{38}$. Making more money available to individuals where salaries are low contributes to poverty reduction ${ }^{39}$. Receipt of per diems also has the potential to increase the personal motivation of staff ${ }^{40}$. Organisational benefits of paying per diems relate to facilitating work getting done by paying the necessary travel expenses, increasing the knowledge base of staff in the organisation by encouraging attendance at training, being a way in which work is recognised, increasing staff productivity and motivation ${ }^{41}$, and increasing spending efficiency by controlling what employees can spend ${ }^{42}$. The perceived benefits of per diems in the development sector and to development agencies are not dissimilar to what has been mentioned above in relation to personal and organisational benefits and again speaks to the idea of incentives/motivations to participate in development projects and to ways of facilitating the uptake of training opportunities. Again people are more likely to attend optional meetings or training at which they will learn new professional skills if their expenses are reimbursed..$^{43}$ But per diems also help development agencies to smoothly implement inservice training programmes by ensuring that a planned number of trainees attend. ${ }^{44}$

The role of per diems as incentives or motivating factors to participate in development projects was also a theme that emanated from the interviews we conducted, although ways were mentioned that this could be mediated. The payment of per diems is a factor that could be influential when project buy-in is negotiated:

People have been exposed to other programmes prior to this one...they benchmarked our programme to the previous programmes they've been involved in. ${ }^{45}$

Per diems are also a way in which to facilitate participation in development projects with low salaries for civil servants given as part of the justification for this. 
Sometimes if people know there is this event [and] there will be allowances, they'll come. Because they want to get their allowances and the allowances are given at the end. That can be enabling...they take it as part of income, but I think their salaries are too low. ${ }^{46}$

Although per diems can be a source of conflict, paying them ensures that work gets done - in that beneficiaries attend and stay motivated, allowing projects (implementers) to meet their goals. That per diems act as incentives for individual participation also means that development agencies benefit.

It's been a source of conflict and issues...on the other hand again it makes sure all the work gets done. ${ }^{47}$

Who does it [paying allowances] reward? It rewards you - the project manager. ${ }^{48}$

The incentive value of per diems are particularly relevant in the context of a lot of donor activity in a particular setting, people having limited time, and donors in a sense vying for the same audiences.

People...will have a number of projects they're working with. Those projects offering the greatest incentives, they'll be motivated to work with them... we manage to deal with that by working long enough in those countries and having trust with those partners. ${ }^{49}$

Another theme that emanated from the interviews that relates to the way in which per diems enable the implementation of development projects concerns the ethical principles that underlie development work. This theme also speaks to the question of to whom per diems get paid: NGO managers, civil servants, or project beneficiaries who are poor. The view of ethical practices in development relates to the idea that projects should not be exploitative and that development 'should not be done on the backs of poor people' even if this just means paying food and transport costs. ${ }^{50}$

If I am asking slum dwellers who are structurally unemployed, structurally malnourished to come to a workshop to talk to me about what's going on in their community, the very least I can do is recognise the higher opportunity costs to that poor person who's just on the edge of surviving. ${ }^{51}$

More disagreement seems to exist about the payment of per diems to government officials and how that enables, or causes barriers in, development projects. Two views exist here one around the ethics of paying people twice for doing similar work which argues against the payment of per diems:

People are already paid in their respective jobs. They get their salary for doing that. It's part of their work. ${ }^{52}$

An opposing view is that it is ethical and fair to pay government officials per diems as it shows that their time is being valued as participation in development projects may fall outside of their normal job description.

The actual functions of the job that you are doing for a [development] partner for me is like an added function. Because...I have my own job description as a government official...So when 
a project comes and says for example...you are an...officer for the project, which means I have to allocate maybe 20 percent of my time doing the project jobs...I need to be paid for that...So because the rules of the game are that you cannot be paid a salary - you can't get two salaries - but I need to get something that can help me to work better in that kind of environment. ${ }^{53}$

A final cluster of ideas around the ways in which the payment of per diems facilitate development that emanated from the interviews is that it has become a standard and expected part of the practice of development - it is simply how the game of development works now, for better or worse. The practice of paying per diems in development projects persists despite more recent efforts from some donors to pull back on these practices or regulate them better. Some interviewees noted that the payment of per diems had not always been the standard practice in carrying out development projects, but that it is now accepted and expected practice and has developed into what has been termed 'a culture'. These interviewees were also of the view that payment of per diems must be seen in the context of the proliferation of NGOs in Malawi, which had not always been the case, and the country's economic situation.

It used not to be like that...But now things have changed. I don't know whether it's due to the coming of several NGOs and different types of funding... ${ }^{54}$

With the NGOs brining in the allowance culture, what came in was that we saw that as people did not have money, they see that there were more donors, more projects, people paid and they seemed to be motivated...the culture has come to stay. ${ }^{55}$

Receiving and distributing per diems is therefore seen as part of the standard practice of development and beneficiaries also know to expect and demand payment of per diems. Beneficiaries know that implementing partners have made commitments to donors for the delivery of certain outcomes which also puts them under pressure to get the work done.

It's a diversion to say 'wow we can't have these workshops unless we pay these guys. They're demanding airfare, they're demanding USD 30 a day in sitting fees because that's what donor $X$ pays'...They just know the game. They know that you are sitting there with a donor-driven project where you've promised the moon to the donor - why not charge you for their time?... [It is about] getting what they have to do versus what you the outsider has to do in order to make donors happy [and] keep your money flowing...So do l...get all moralistic about it or do I see that it's a larger system that forces people to be less than their best. ${ }^{56}$

If we consider per diems from this abovementioned positive perspective where they are seen as both a support to income, a motivator of participation, and a part of the standard practice of development project implementation it then can be drawn upon that per diems create a sense of surety that the stakeholders of a project will remain invested in the project throughout its life cycle. This sense of surety facilitates conceptualization and planning where project or programme managers are assured of the participation of the various actors that are required for a project's success. In essence this sense of surety also assists the implementation of a project: there is an agreed standard of the additional remuneration being received outside of a salary to support the work that must be achieved. Per diems therefore can translate into higher expectations and guarantees of achievement by role players. 


\section{Per diems as a barrier in development projects}

The ways in which per diems act as barriers in the development context are highlighted in the literature and can be grouped around three general areas.

The first of these areas is that per diems can lead to the abuse of the donor funding system. This abuse can take a number of different forms such as the falsification of records in order to obtain payment of more per diems, ${ }^{57}$ delaying duties to clock overtime, double-dipping, exaggerating number of days worked, skimming days (doing work in less time but keeping the full per diem), workshop fraud (falsifying participant lists), etc. ${ }^{58}$

The second way in which per diems can act as a barrier relates to human resources and includes aspects such as how people allocate their time and what acts as intrinsic or extrinsic motivating factors. Per diems can create conflict in teams between those receiving per diems and those who are not. ${ }^{59}$ Per diems can affect productivity and can lead to task shifting, for example staff who do not have work opportunities where per diems are paid become less productive or avoid tasks that do not have per diems linked to them ${ }^{60}$. Per diems and other allowances have been shown to distort human resource management systems. This happens when staff move their focus rom routine tasks to workshop attendance or other programmespecific activities to which per diems have been allocated ${ }^{61}$. Just as per diems encourage senior managers to attend training instead of sending their subordinates, the incentive of per diem revenue encourages high-level government officials to attend meetings and conferences rather than fulfilling administrative tasks that would require time at their desks. For example one government official in Ethiopia claimed that donor organisations were out-bidding each other, paying higher and higher per diems and drawing staff away from their jobs $^{62}$. The payment of per diems also affect people's norms and intrinsic motivation for performing certain tasks: people are perceived as reluctant to do even the smallest tasks without receiving a per diem. ${ }^{63}$ Finally, the payment of per diems can have an effect on workforce retention. The argument here, specific to projects in the health sector, is that inservice training does not lead to retention in the health system, but people change career paths and want to instead work for international development organisations, while international development organisations see such training as a recruitment opportunity. ${ }^{64}$

Thirdly, per diems can act as a barrier in the effect that it can have on services or development outcomes. As example, per diems can have a geographic effect on the quality of services provided as it tends to be staff from urban areas that capitalise on training opportunities at the expense of their rural counterparts. ${ }^{65}$ The payment of per diems furthermore inflates the cost of services and therefore does have an effect on the value for money component of development. ${ }^{66}$ Another example of inflated costs relates to the discussion around where training programmes are hosted. An argument is made that training or meeting participants can better focussed if the meeting is held off-site, although some evidence suggests that residential training programmes are no more effective than non-residential programmes, yet residential programmes may cost a lot more due to the expenses of accommodation and allowances. An example of this is in Zambia where residential training in child health management cost twice as much as non-residential training, yet skills and knowledge of participants tested at three and six months after training were about equal. ${ }^{67}$ The payment of per diems also has an effect on who attends workshops and that can have an effect on how 
the training received translates into the development outcomes. Sometimes people attend workshops unrelated to their work targets or more senior people attend them in order to collect per diems ${ }^{68}$. Capacity-building is therefore affected with resultant poor application of learning. ${ }^{69}$ It is also not unusual for development agencies to engage in price competition to get the participants they need when conducting training on the same day, ${ }^{70}$ and although such competition might not be negative per se, it could disproportionally inflate the budgets of development projects.

Data from the interviews and from our own experience match the barriers discussed in the literature, but also points out additional ways in which per diems can act as barrier. Although some of the interviews hinted at the abuse of the system (for example asking for lunch allowances when a meeting was not held close to lunchtime or deliberately organising meetings close to lunchtime in order to get a lunch allowance), more interviewees referred to inconsistencies in the way in which the payment of per diems is managed as a barrier. There are rules and guidelines which help manage the payment of per diems, both internal policies for donor agencies and in-country agreements between governments and donors. But how these guidelines are managed can act as a barrier to implementing development projects because although governments and donors might have agreed rates, some civil servants privately do not agree with these rates, or rates differ between donors and between donors and government.

You'll find yourself invited to a government activity...you may find something different...and they'll say no we're following USAID regulations because this is USAID money... ${ }^{71}$

I know recently in Malawi the government released a circular...to say 'no allowances'...You'll find some government officials have said in some meetings that I was attending... 'OK, you go ahead with [implementing] this circular...You won't see us - we'll simply tell you we are busy'. $^{72}$

Government [and] the donors issue their stances on allowances from time to time. Now there are times where government and donors seem to differ in defining the allowances to be paid...There are times when the donors even among themselves, you'd find [differences in rates]...and it has really been impacting on implementation... because the culture has come to stay, if you come and doesn't want to provide allowances like another organisation does, people will shun what this organisation is doing. ${ }^{73}$

According to the data per diems can also cause barriers related to human resources, and particularly people's motivation. A number of interview participants mentioned the consequences of not being willing or able to pay per diems which is an inhibiting factor as it negatively affects participation in development projects. There are also indications of a culture of work getting done only when beneficiaries are being paid per diems. The payment of per diems makes it difficult to assess people's real or underlying interest in a project as there are indications that projects are compared to one another in terms of the financial benefits on offer.

It depends on how people might look at it: it might create a culture of saying that you can only participate in something if you are paid for it. ${ }^{74}$ 
For me it looks like a culture...a learned culture...so to deal with this culture it's difficult because the beneficiaries have been exposed to this way of doing things in terms of managing this kind of culture...And if we give them [per diems], we have to give more [money than other projects]. ${ }^{75}$

Personally I am against per diems as a secondary form of remuneration - they have negative incentive effects where you end up with people who attend events or processes because of the money and not for the cause. This is a tough challenge and environment to operate in.... If nobody attends [an event] because there is no per diem then it is a good indicator of the poor relevance and importance of the meeting or process in the first place. ${ }^{76}$

The interviews and our experience also illustrate that per diems can have an impact on services and the outcomes of projects in a number of ways: the wrong people attending the meetings which affects application of learning, donor competition for the same audience, and too many development projects and therefore a struggle to motivate people to participate. Donors also expect value for money and the payment of per diems goes contrary to that.

If you don't have money to give them [beneficiaries]...then what happens? They will not come. $^{77}$

They [per diems] are massively destructive of projects. All of our donors expect value for money...the biggest cost we have is around incentives...and per diems. ${ }^{78}$

An aspect not mentioned in the literature is the difficulties that the payment of per diems can create for local NGOs as they have to operate in the space between beneficiary expectations about per diems and what funders are willing to pay.

As has been mentioned there are positive impacts of per diems from a project management perspective in the conceptualization and implementation phase of a project. However when misused, the consequence of a per diem becoming a means through which leverage is created, where individuals consider per diems as a bargaining tool and threaten the successful completion of a project, one must consider whether they are worth their weight in gold. The implementation and reporting stage of a project can become somewhat precarious. The implementation of a project can be derailed with poor or non-participation of actors, consequently reporting on project goals and objectives as well as effective measuring and evaluating of a project is brought into question.

\section{Analysis and reflection on the effect of per diems on the entire project cycle}

A summary of the literature, reflection on our own experience, and interviews with others working in the field of international development illustrate that per diems are enablers in various ways and can act as barriers in other ways as discussed above. Per diems act as enablers in that they are extrinsic motivating factors for people to participate in development projects and therefore facilitate development efforts. In this sense they have become part of the bigger context in which development in takes place and in some ways standard development practice. The argument here is that it is ethical to pay people for their time and not to run projects that might indirectly exploit people. But per diems also act as barriers in the development process as they lead to an abuse of the donor funding system, negatively 
impact on people's motivation and the projects people participate in, which in turn affects development outcomes. The literature also speaks to various context factors that facilitate the existence of the system, such as the habit that has now been created of paying per diems, and the concomitant expectations that have been created. Other contextual factors include poverty, salaries that might need to be topped-up (although it is important to compare such salaries with those of others in equivalent positions in different professional fields), and salaries being paid late or at all, which creates problems with cash flow.

Per diems are clearly not just barriers or enablers but are both, and can have an impact on different dimensions of the project cycle. The data and literature combined suggests that per diems can act as barrier and enabler at various stages of a project. This way of looking at the effects of per diems, and illustrating the extent of their effects, is currently absent from the literature. The influence of per diems, either as barriers or enablers, at different points in the lifecycle of a development project is illustrated in the diagram below which draws from the previous two sections of this paper on how per diems act as barriers and enablers. Here it can be seen that per diems are relevant from the point of project conceptualisation and design as it influences buy-in into projects - projects are compared, and there is a 'cultural expectation' of payment of per diems. Per diems also have a strong enabling or barring influence at the implementation stage of a project where it could act as motivating factor and incentive to get work done, but also be an extrinsic incentive that makes it difficult to establish people's 'real' motivations. Per diems also play a role in the final delivery of services or project outcomes, for example paying per diems could skew capacity in certain geographic areas as people from more urban areas make use of training opportunities, there can be poor application of learning if the wrong people attend workshops, and per diems inflates project costs and goes contrary to the idea of value for money in development.

The literature and interview data also illustrate that the project cycle and the ways in which per diems influence the different dimensions is situated within three layers of broader contextual influences. The first layer is the management of the per diem system which includes aspects such as standardisation (the lack or inconsistent application thereof). The second layer are the various contextual factors that facilitate the existence of per diems, such as poverty, low salaries, and multiple development projects in which people participate. The final layer is the larger context of international development practice in which all of these development activities and the practice of paying per diems are taking place. This layer includes aspects such as a system introduced by donors that is now widely practiced and demanded, and donors competing against one another for the same audience while trying to practice development in a way that does not exploit people. 


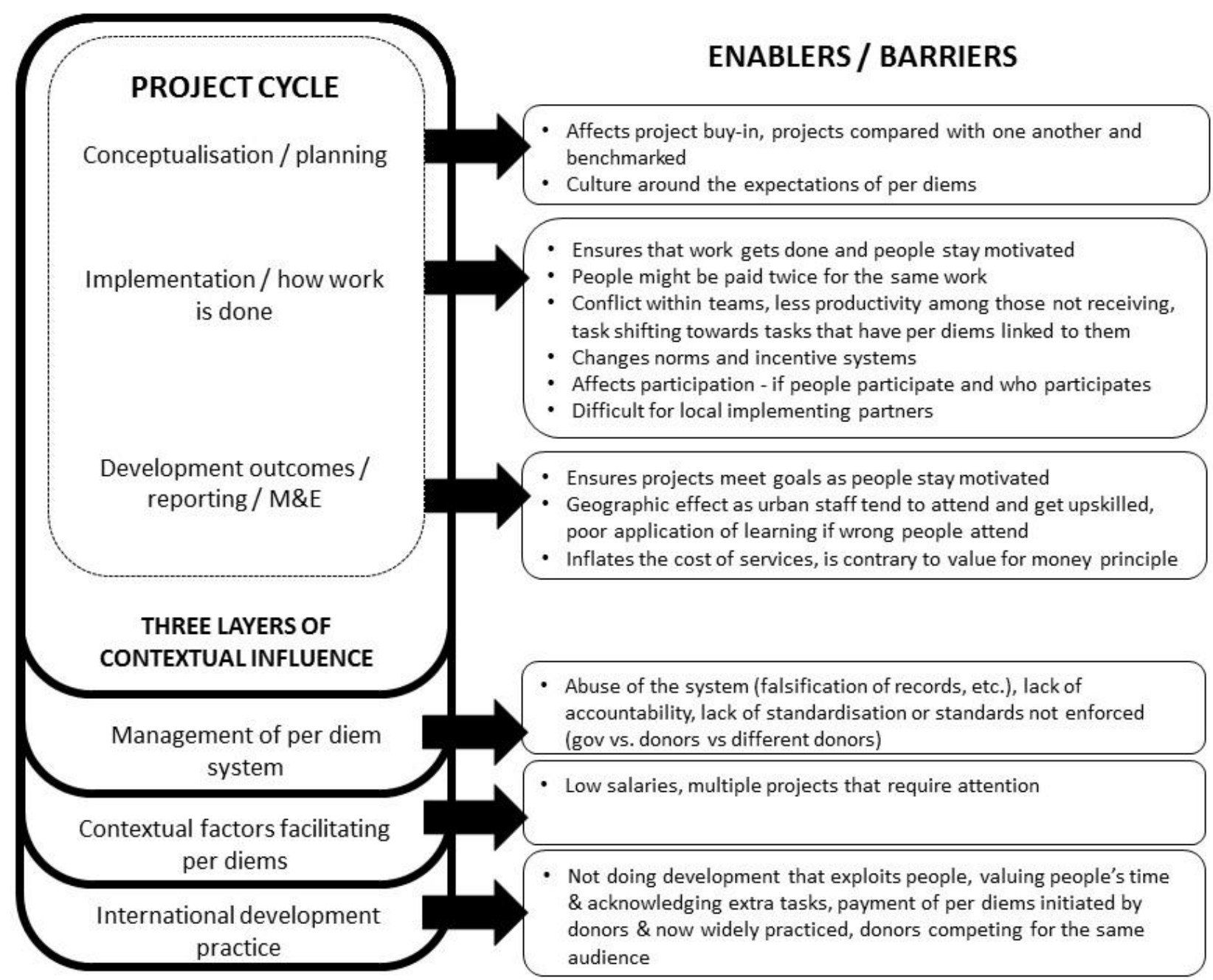

\section{SOLUTIONS IN THE} LITERATURE

\section{Reporting from people on}

training received

Standardisation, improving

compliance and transparency

Paying salaries on time,

increasing salaries

Figure 1: Influences of per diems on the project cycle in international development projects 
As illustrated in the diagram, in the literature, as well as the interview data, when people speak about solutions to some of the barriers caused by the payment of per diems, or alternatives to per diems, the majority of suggestions are around better or different management of the per diem system, e.g. standardising rates across organisations and better enforcement of these standards; involving a wide range of stakeholders in discussions about how per diems should be regulated; and improving the monitoring, control, transparency of and compliance to the per diem system. ${ }^{79}$ Others focus on trying to address the contextual factors that facilitate the payment of per diems by increasing salaries and paying salaries on time, doing away with discretionary allowances (adding a pre-determined amount to salaries instead); and striving for comparable salaries irrespective of whether an individual works for a local NGO or an international donor agency. ${ }^{80}$

Using the diagram as a reference point, there appears to be many questions around per diems that still require answering, for example: with such a focus on improving the management of the per diem system, are there best practices or examples that we could learn from where the payment of per diems is working well? If the payment of per diems is a system that is here to stay (to some extent), what efforts are there at an international level between donor agencies to address these issues and/or standardise the practice? How are development efforts addressing the contextual factors such as poverty and low salaries that feed into the facilitation of this system of paying per diems? If a contributing factor is that donors are vying for the same audiences, how can in-country efforts be better coordinated to reduce this competition? What are the costs and benefits from a development ethics perspective of continuing with the practice of paying per diems? These are some of the questions that still require answering when debating the payment of per diems as a barrier or enabler to international development projects in Africa.

\section{Conclusion}

This paper has explored how the payment of per diems can act as enablers and barriers in international development projects, drawing on existing literature, experience of programme implementation in Malawi, and interviews with others working in the development sector (civil servants, donors, local and international NGOs). It has illustrated the complexities around this topic, as well as its pervasiveness in the effect that it has on different aspects of the project cycle - something that the literature to date has not illustrated. The paper has taken the discussion beyond the health sector which is the focus of much of the existing literature and into the development field more broadly. We hope that this is part of a wider and open discussion on per diems and concur that a large-scale survey is needed to fully understand the nature and extent of the payments of per diems internationally. ${ }^{81}$

\section{Notes and References}

\footnotetext{
${ }^{1}$ Acknowledgements: [Text removed for the purposes of anonymization during peer review]

${ }^{2}$ Vian, T., Miller, C., Themba, Z. and Bukuluki, P., 2013. Perceptions of per diems in the health sector: Evidence and implications, Health Policy and Planning, vol 28, 237-246, p238.

${ }^{3}$ Conteh, L. and Kingori, P., 2010. Per diems in Africa: A counter-argument, Tropical Medicine and International Health, vol 15, no 12, p1553-1555.
} 
${ }^{4}$ Nkamleu, G.B. and Kamgnia, B.D., 2014. Uses and abuses of per-diems in Africa: A political economy of travel allowances. African Development Bank Group, Working Paper Series, no 196, February 2014. Chêne, M., 2009. Low salaries, the culture of per diems and corruption, U4 Expert answer Available at http://www.u4.no/helpdesk/helpdesk/query.cfm?id=220, [Accessed on 14 October 2016]. Søreide, T., Tostensen, A. and Skage, A., 2012. Hunting for per diem: The uses and abuses of travel compensation in three developing countries, Norad Evaluation Department, Report 2.

${ }^{5}$ Vian, 2013, p238.

${ }^{6}$ Ridde, V., 2010, Per diems undermine health interventions, systems and research in Africa: Burying our heads in the sand. Editorial. Tropical Medicine \& International Health, July 28.

${ }^{7}$ Bryce, J., Cutts, F., Naimoli J.F. and Beesley, M., 1993. What have teachers learnt? Lancet, vol 342, $160-161$.

8 [Text removed for the purposes of anonymization during peer review]

${ }^{9}$ Vian, 2013, p244.

${ }^{10}$ Aiga, H., 2012. Train to retain or drain? The need for a global survey for sitting allowances, Public Health, vol 126, pp620-623.

${ }^{11}$ Conteh, L. and Kingori, P., 2010.

${ }^{12}$ Nkamleu and Kamgni, 2014. Søreide et. al. 2012 p3. Vian, 2013, p238.

${ }^{13}$ Nkamleu and Kamgni, 2014

${ }^{14}$ Vian, 2013, p238.

${ }^{15}$ Nkamleu and Kamgni, 2014.

${ }^{16}$ Søreide et al, 2012 p6.

17 Ibid.

18 Ibid., p18.

19 Ibid., p40.

${ }^{20}$ Vian, 2013, p239.

21 Ibid., p239-240.

${ }^{22}$ Conteh and Kingori, 2010, p1553.

${ }^{23}$ Søreide et al, 2012, p3. (Chene 2009: $x$ )

${ }^{24}$ Therkildsen, O. and Tidemand, P., 2008. Staff management and organisational performance in Tanzania and Uganda: Public service perspectives. Copenhagen: Danish Institute for International Studies.

${ }^{25}$ Roenen, C., Ferrinho, P. and Van Dormael, M., 1997. How African doctors make ends meet: An exploration, Tropical Medicine and International Health, vol 2, p127-135.

${ }^{26}$ Scotland Malawi Partnership. 2014. Practical guidance and support on per diems. Available at http://www.scotland-malawipartnetship.org/resources/?type=298 [Accessed on 14 October 2016]

${ }^{27}$ Ridde, 2010.

${ }^{28}$ Conteh and Kingori, 2010, p1554.

${ }^{29}$ Scotland Malawi Partnership, 2014,p2-3.

${ }^{30}$ Aiga, 2012, p620.

${ }^{31}$ Conteh and Kingori, 2010, p1553.

${ }^{32}$ Ibid.

${ }^{33}$ Vian, 2013, p238.

34 Ibid.

${ }^{35}$ Boyatzis, R.E. 1995. Transforming qualitative information: Thematic analysis and code development. SAGE Publications

${ }^{36}$ Aiga, 2012. Vian 2013.

37 Vian, 2013, p240. Aiga, 2012, p621.

${ }^{38}$ Vian, 2013, p240.

39 Ibid.

$40 \mathrm{lbid}$.

${ }^{41}$ Ibid.

42 Vian, T., 2009. Benefits and drawbacks of per diems Do allowances distort good governance in the health sector? U4 Brief No. 29. Bergen, Norway: CMI, U4 AntiCorruption Resource Centre. Available at http://www.U4.no [Accessed on 14 October 2016]. Nkamleu and Kamgni, 2014.

${ }^{43}$ Vian, 2009, p1. Nkamleu and Kamgni, 2014.

${ }^{44}$ Aiga, 2012, p622.

${ }^{45}$ Respondent, International Development Programme

${ }^{46}$ Respondent, Local NGO

${ }^{47}$ Respondent, Local NGO 


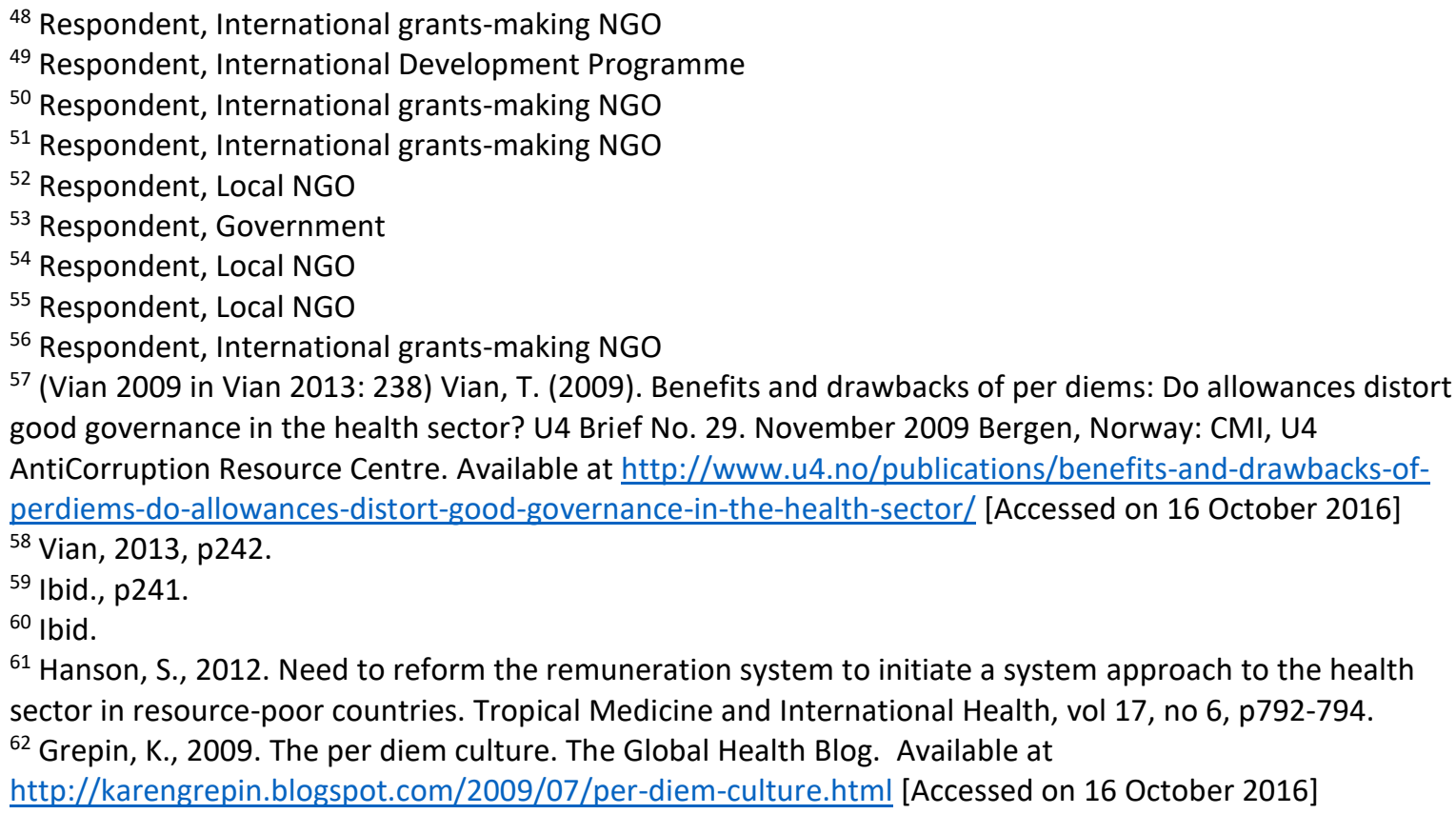

${ }^{67}$ Mukuka, C. 2004. Integrated management of childhood Illness in Zambia: A report on the documentation of the $\mathrm{IMCl}$ experience, progress, and lessons learned. WHO Regional Office for Africa. Available at http://www.afro.who.int/whd2005/imci/zambia.pdf [Accessed on 11 August 2016]

${ }^{68}$ Vian, 2009.

${ }^{69}$ Aiga, 2012, p621.

$70 \mathrm{lbid}$.

${ }^{71}$ Respondent, Local NGO

72 Respondent, Local NGO

${ }^{73}$ Respondent, Local NGO

${ }^{74}$ Respondent, Government

${ }^{75}$ Respondent, International Development Programme

${ }^{76}$ Respondent, International Donor Agency

77 Respondent, Local NGO

78 Respondent, International Development Programme

79 Vian, 2013, pp243-244. Aiga, 2012. Vian, T. and Sabin, L., 2012. Per diem policy analysis toolkit U4 Brief No. 8. December 2012, Bergen, Norway: CMI, U4 AntiCorruption Resource Centre. Available at: pttp://www.cmi.no/publications/file/4680-per-diem-policy-analysis-toolkit.pdf [Accessed on 5 August 2016] ${ }^{80}$ Conteh and Kingori, 2010, p1554. Vian, 2013, p243. Vian and Sabin, 2012, p5.

${ }^{81}$ Aiga, 2012. 